\title{
Measurement of platelet adhesiveness including the use of diatomaceous silica (celite)
}

\author{
G. D. PEGRUM, S. SHAW, AND SYLVIA E. WOLFF \\ From the Department of Haematology, Charing Cross Hospital and \\ Medical School, London
}

SYNOPSIS Methods of platelet adhesiveness to glass and celite have been developed. The technical merits of these methods have been compared with a method using adenosine diphosphate (ADP). The aspects of platelet stickiness measured by the various techniques may be somewhat different. Bearing this in mind, the reproducibility of the results using each of the three methods has been assessed on a series of healthy donors.

During the past two years we have been investigating some aspects of platelet adhesiveness. Whole blood was used in our studies to keep the experimental conditions as uniform as possible. Marked variation in stickiness has been demonstrated using methods where the red cells are removed (Hellem, 1960).

Detailed investigations were made of an experimental method using glass microspherules (ballotini), and a similar procedure using diatomaceous silica (celite) was developed. The adenosine diphosphate (ADP) method of Eastham (1964) was also used. After establishing reproducible conditions in each case, adhesiveness was measured on a series of normal subjects to find a normal range for each method.

As indicated by O'Brien (1966), the factors concerned in the adhesiveness of platelets are complex and there may be little value in directly comparing the adhesiveness observed by different methods, as these may well measure different aspects of platelet function. In this paper no attempt has been made to compare the degree of adhesiveness found in normal donors using each technique. However, we were concerned to develop a simple method of estimating platelet adhesiveness with a reproducible normal range in healthy donors under defined experimental conditions.

\section{MATERIALS AND METHOD}

In these studies all blood samples were taken, using a number 1 needle and a plastic syringe, from a vein in the antecubital fossa distended by gentle constriction above immediately before collection. Blood samples were taken at various times during the day and had no particular

\footnotetext{
Received for publication 9 September 1966.
}

relation to food, smoking, or exercise. The experiments were all carried out at room temperature.

Polystyrene bottles $\left(2 \frac{1}{2}\right.$ in. $\times 1$ in.) were used for all blood specimens. Ethylenediamine tetra-acetic acid (E.D.T.A.) was used to give a blood concentration of more than $4 \mathrm{mM}(2 \cdot 4 \mathrm{mg}$. E.D.T.A. added to the container) and heparin was used in a concentration of 100 units/ml. The method for counting platelets was essentially that described in the M.R.C. memorandum no. 32 (1955). All platelet counts were done in duplicate and the average taken. The counts were repeated if there was a discrepancy greater than $15 \%$.

In the celite (silica) and glass microspherule (ballotini) methods, samples for platelet counting were taken from the particle-free upper layer after the container had been placed on a flat surface for two minutes. It was found that in controls with E.D.T.A. alone, there was no significant difference in platelet counts performed immediately after mixing or after standing for two minutes.

1. CELITE ${ }^{1}$ Blood, $2 \mathrm{ml}$., was added to each of two polystyrene bottles containing E.D.T.A. Both were placed on a Matburn wheel to ensure thorough mixing at $\mathbf{3 0}$ r.p.m. Celite was previously washed twice with $5 \% \mathrm{HCl}$ and then 15 times with distilled water and dried at $100^{\circ} \mathrm{C}$. Celite, $0.5 \mathrm{~g}$., was added to one of the E.D.T.A. blood samples and both specimens returned to the wheel. After adequate mixing a sample for counting platelets was taken from the E.D.T.A. bottle. At 45 minutes the sample to which the celite had been added was removed for a platelet count.

The adhesive platelet count was the difference in the number of platelets counted in the two specimens, expressed as a percentage. It was found later that the same results were obtained using one E.D.T.A. bottle, the control count being taken before the addition of celite. Optimal reproducible conditions were obtained after varying the quantity of celite between $0.3 \mathrm{~g}$. and $1 \mathrm{~g}$.

\footnotetext{
${ }^{1}$ Manufactured by Johns Manville, U.S.A.
} 


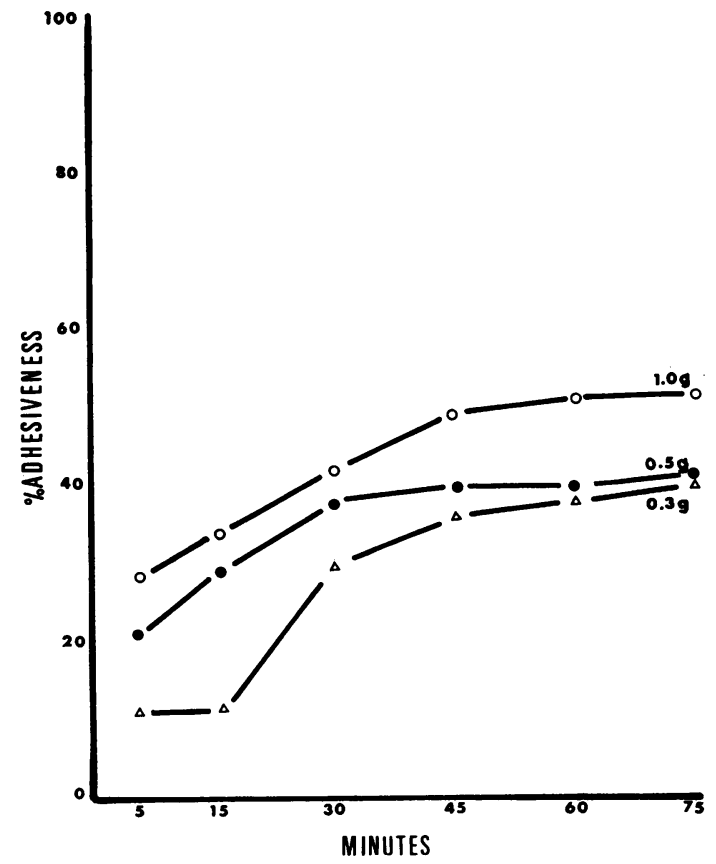

FIG. 1. Variations in adhesiveness using increasing amounts of celite with different contact times.

The time of contact with the celite was varied between five and 75 minutes (Fig. 1).

Celite 560 was found to be the most suitable in view of the particle size.

GLASS MICROSPHERULES (BALlotini) Blood, $2 \mathrm{ml}$., was added to each of two polystyrene bottles containing E.D.T.A. Both were placed on a Matburn wheel to mix at 30 r.p.m., and $3 \mathrm{~g}$. of ballotini of a diameter between 0.102 and $0.0124 \mathrm{~mm}$. was added to one of the E.D.T.A. blood samples, and both specimens returned to the mixer. After adequate mixing a sample for counting platelets was taken from the E.D.T.A. bottle. At 35 minutes the sample to which ballotini had been added was removed for a platelet count. The adhesive platelet count was the difference in the number of platelets counted in the two specimens. As in the celite method, later tests were performed using one E.D.T.A. bottle, the control count being taken before the addition of ballotini. The optimum quantity of ballotini and the mixing time were determined after preliminary trials in which the amount of ballotini was varied between $2 \mathrm{~g}$. and $5 \mathrm{~g}$. and the time for mixing between five and 75 minutes (Fig. 2).

ADENOSINE DIPHOSPHATE (ADP) The method used was essentially that described by Eastham in 1964. Blood, $2 \mathrm{ml}$., was added to $2.4 \mathrm{mg}$. E.D.T.A. and to $2 \mathrm{mg}$. heparin in separate polystyrene bottles and both placed on a Matburn mixer at 30 r.p.m., then $0.04 \mathrm{ml}$. of ADP solution was added to the heparinized blood sample. The ADP was taken from a stock solution of $5 \mathrm{mg}$. in

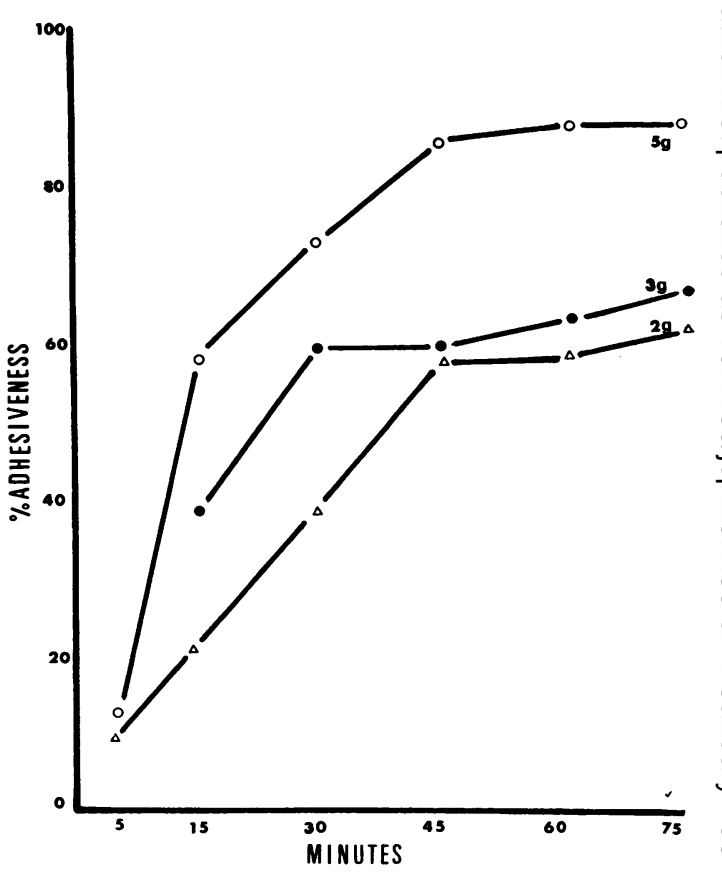

FIG. 2. Variations in adhesiveness using increasing amounts of ballotini with different contact times.

$20 \mathrm{ml}$. saline freshly prepared or stored for up to three months at $-20^{\circ} \mathrm{C}$. in $0.5 \mathrm{ml}$. aliquots. The bottle was $\unrhd$ returned to the mixer and after exactly 30 minutes the $\overrightarrow{\vec{F}}$ ADP-treated sample was transferred to a further polystyrene bottle containing $2.4 \mathrm{mg}$. E.D.T.A. and mixed for 20 minutes. Platelet counts were performed on each sample. It was found that the sample must be mixed for at least 20 minutes to obtain reproducible counts. After $\overparen{O}$ the addition of E.D.T.A. to the ADP-treated sample both specimens could be left at $4^{\circ} \mathrm{C}$. up to 24 hours without significant changes in the platelet count, providing they were mixed for 20 minutes before counting. The adhesive platelet count was obtained from the difference in counts between the two samples.

These methods were applied to a series of healthy $D$ donors whose ages varied between 17 and 68 years. Five geriatric patients aged 70 to 85 years who were not $\vec{N}$ suffering from any major systemic disorder were included $\sigma$ to observe platelet adhesiveness in a wider age group.

\section{RESULTS}

ADHESIVENESS USING CELITE This method was carried $\frac{\mathrm{C}}{\mathrm{D}}$ out on 66 subjects (47 males and 19 females) whose ? ages varied between 16 and 85 years. The results are $\tau$ shown in Figure 3. The average mean adhesiveness

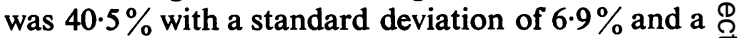
standard error of \pm 0.85 . We based our normal $\vec{D}$ range on twice the standard deviation which was

,




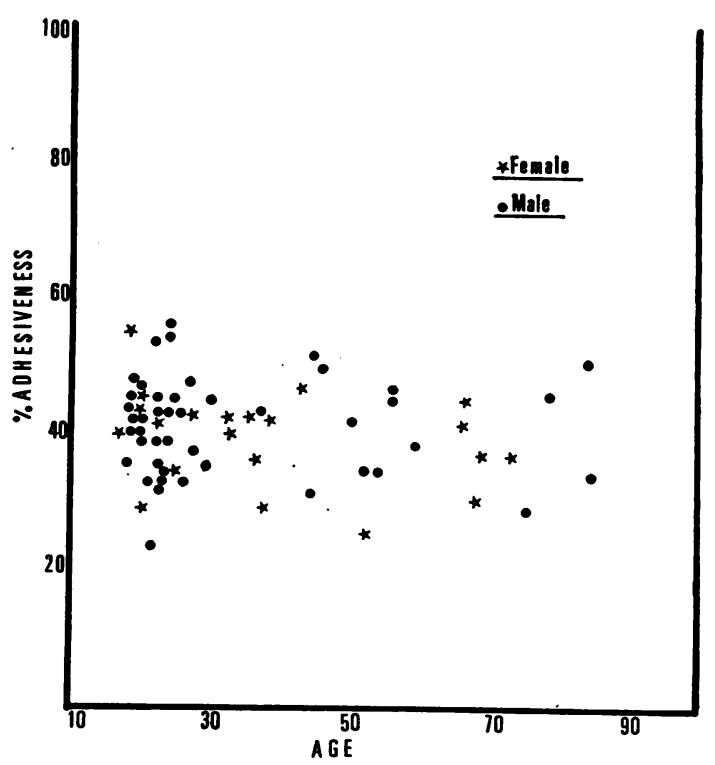

FIG. 3. Results of method using celite.

$26.5 \%$ to $54.5 \%$. Three observations were outside these limits, two above and one below. These were all in the age group 18-23 years. There was no significant difference in the results between the two age groups, up to 40 years and above 40 years $(P=$ 0.6). There was no difference between males and females $(P=0 \cdot 6)$.

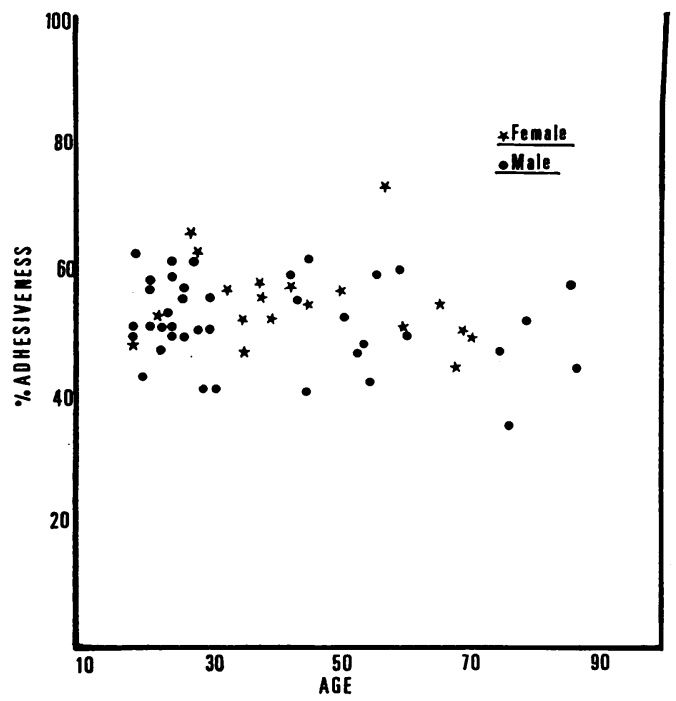

FIG. 4. Results of method using ballotini.
ADHESIVENESS USING GLASS MICROSPHERULES This method was performed on 58 subjects ( 39 males and 19 females) aged 16-85 years; results are shown in Figure 4. The average mean adhesiveness was $54 \%$ with a standard deviation of $6.8 \%$ and a standard error of \pm 0.89 . Our normal range of $40.5 \%$ to $67.5 \%$ was based on twice the standard deviation. Two observations fell outside these limits, one above and one below, in two subjects of 57 and 76 years respectively. There appeared to be a difference between males compared with females $(P=0.025)$ but no significant difference between the two age groups below and above 40 years $(P=0.7)$.

ADHESIVENESS USING ADP Sixty-seven subjects (41 males and 26 females) were studied, aged between 16 and 85; the results are shown in Figure 5. The

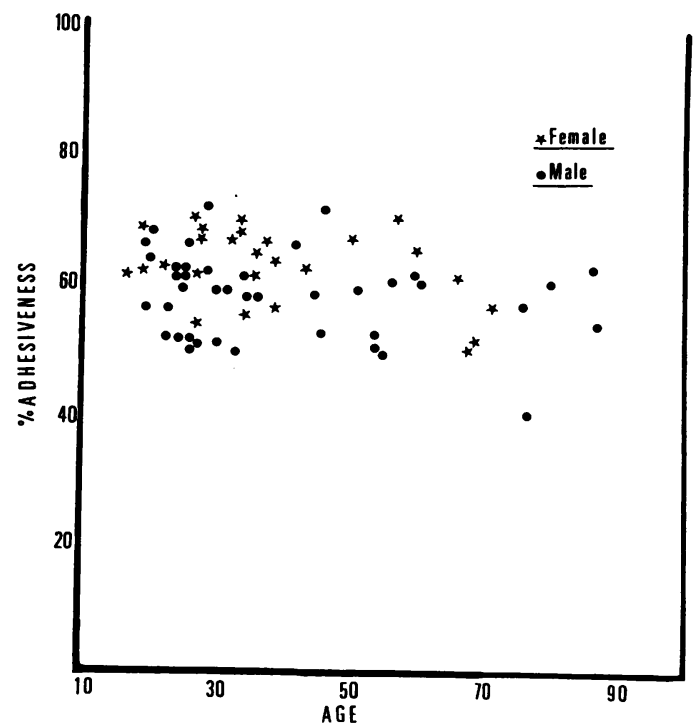

FIG. 5. Results of method using adenosine diphosphate.

average mean adhesiveness was $60.5 \%$, standard deviation $6.35 \%$, and the standard error \pm 0.78 . Our normal range of 48 to $73 \%$ was calculated on twice the standard deviation. One observation on a 75-year-old man was below this range. There was no significant difference in the results when correlated with age $(P=0.7)$ but there was an apparent difference between males and females $(P=0 \cdot 01)$.

The platelet adhesiveness in 35 of our subjects was tested using each of the three techniques on the same blood sample.

\section{DISCUSSION}

The stickiness of platelets either to one another or to 
foreign surfaces seems likely to play a vital part in haemostasis and thrombosis. Many attempts to measure this property have been made; these have principally involved platelet aggregation produced by various substances, especially ADP (Gaarder, Jonsen, Laland, Hellem, and Owren, 1961 ; Born, 1962) and the adhesion to foreign surfaces, especially glass (Hellem 1960; Salzman, 1953). We concerned ourselves mainly with the latter property of platelets. The factors influencing the adhesion of platelets are complex and ill defined. Hellem (1960) and later others, including Salzman (1953), have studied many of the experimental conditions which influence adhesion to glass surfaces.

Initially we wished to establish a method using glass microspherules as a routine procedure in our laboratory. The conditions of the experiment were so designed as to give us an adhesiveness of about $50 \%$ with healthy donors so that later when studying patients with various disorders we could allow for considerable variation in stickiness.

The control subjects were chosen from healthy people but we were only able to study approximately half the number of females to males. There was a difference in the results comparing males and females using ballotini and ADP. These results appeared statistically significant but the total number of females was small and this may well have biased the results There was no apparent difference in adhesiveness in the age groups.

Because of the known variations in adhesiveness to glass with changes in haematocrit (Hellem, 1960) and possibly platelet numbers (Stormorken, LundRiise, and Rørvik, 1965) we did not incude any person with a haematocrit below $35 \%$ or above $48 \%$ in any of the experiments, likewise all the platelet counts were within normal limits. Some experiments were carried out artificially, changing the haematocrit and platelet counts. The results, however, were found to be somewhat haphazard and did not show any consistent pattern with either variable. These results were thought to be due to the changes produced by manipulations necessary to increase or decrease the haematocrit or platelet count. Using three anaemic patients and correcting their haematocrit in vitro with their own red cells we did not find any constant or significant change in the adhesiveness with glass microspherules or the A.D.P. techniques, but some slight variation was observed in adhesion to celite in one patient.

The method using glass microspherules was not entirely satisfactory. Platelets tend to become 'damaged' and are often difficult to count. The accuracy of the weighing of the glass microspherules is absolutely critical.

Latex particles (Glynn, Movat, Murphy, and
Mustard, 1965), amnion (O’Brien, 1961), yeasts (Roskam, 1961), and fatty acid (Haslem, 1964) have been shown to encourage platelets to adhere. This suggested the possibility of using another agento to record platelet stickiness.

Diatomaceous earth, celite 560 , was found to $\frac{\overline{\bar{m}}}{\overline{2}}$ give a suitable surface for platelets to adhere to $\mathbb{\complement}$ and control conditions were established using this substance: the advantage was that visual platelet ${ }^{\text {s }}$ counts were easier, but care during sampling was. essential so as not to remove celite particles.

We found a slightly wider range with the normal subjects examined when compared with the range용 obtained by our other methods.

The method of Eastham (1964) was carried out in? parallel with the other two methods in order to have $\vec{s}$ some comparison of the reproducibility of techniques $\sigma$ in our studies. It is reasonable to suppose that we ? were not, in fact, measuring the same aspect of platelet function when using ADP celite, or ballotini, though it is probable that ADP is in- $\frac{C}{d}$ volved in each process (Gaarder et al., 1961). Col₹ lision factors between platelets and other surfaces, $\vec{c}$ which are probably highly relevant (O'Brien, 1966), क्षे must also differ significantly in each of the threemethods. However, we were primarily concernedo with establishing laboratory methods of the adhesiveness which would be reproducible and simple, fully realizing that the particular facet of plateleto adhesion that we are assessing may be different in each method. Biggs and Macfarlane (1962) have $\overrightarrow{\vec{F}}$ pointed out that in adhesive methods 'such surfaces may have stimulated platelet disintegration, or? clumping without adhesion thus reducing the number available for counting independently of the loss due to adhesion'.

It was decided to consider these procedures in regard to their technical advantages rather than speculate as to which aspect of stickiness we were in fact observing. Further, we appreciated that in each aspect of the technique, slight variations such? as different batches of ADP, different qualities of glass, varying size of containers, and temperature. variation may alter the results significantly. E.D.T.A N was used as the anticoagulant, so that later this might facilitate the introduction of these techniques into routine practice.

We found the narrowest average mean whetr using Eastham's method and in this respect it wa\& superior to the other procedures. The method using microspherules gave a closer mean average than that with celite, but was technically more difficult.

The results in our experiments depended on error which arise from visual platelet counting. We toolf care to reduce these errors by duplicating counts? However, electronic counting if sufficiently accurate 
and reliable could speed the technique and reduce the tedium of visual counting.

We would like to thank the Sub-Committee for Clinical Research, Charing Cross Hospital, for financial support, and Miss P. M. Turnbull of the photographic department of Charing Cross Hospital and Medical School for the photographs of the figures.

\section{REFERENCES}

Biggs, R., and Macfarlane, R. G. (1962). Human Blood Coagulation and its Disorders, 3rd ed., p. 267. Blackwell, Oxford.

Born, G. V. R. (1962). Nature (Lond.), 194, 927.
Eastham, R. D. (1964). J. clin. Path., 17, 45.

Gaarder, A., Jonsen, J., Laland, S., Hellem, A., and Owren, P. A. (1961). Nature (Lond.), 192, 531.

Glynn, M. F., Movat, H. Z., Murphy, E. A., and Mustard, J. F. (1965). J. Lab. clin. Med., 65, 179.

Haslem, R. J. (1964). Nature (Lond.), 202, 765.

Hellem, A. J. (1960). Scand. L. clin. Lab. Invest., 12, suppl. 51.

Macfarlane, R. G., and Biggs, R. (1955). Memor. med. Res. Coun. (Lond.), 32.

O'Brien, J. R. (1961). J. clin. Path., 14, 140.

(1966). Ann. Rev. Med., 17, 275.

Roskam, J. (1961). In Blood Platelets; Henry Ford Hospital International Symposium, edited by S. A. Johnson, R. W. Monto, J. W. Rebuck, and R. C. Horn, Jr., p. 153. Churchill, London. Salzman, E. W. (1953). J. Lab. clin. Med., 62, 724.

Stormorken, H., Lund-Riise, $\AA$, and Rørvik, T. O. (1965). Scand. J. clin. Lab. Invest., 17, suppl. 84, 183. 